\title{
THYROID GLAND.
}

Garré (Tubingen).-Injition Traatment in Guitrus. "Corresphl. fuir Sichwuizer Aerzte," I $S_{94}$, No. I3.

THE author has made experiments with injections of iodoform into the veins, and has found that they are without any danger, and are not followed by thrombosis; there is, therefore, no danger if the veins in a goitre should be injected.

Hichacl.

Ström, H. V. (Christiania).-Some Opirations for Goitri. "Tidsskrift for den Norske Laegeforening," I $\delta 94$, No. 7.

REPORT of five cases of goitre operated upon: two cases of follicular goître (partial strumectomy); one case of fibrous, and one of vascular goitre (partial strumectomy); and one case of cystic goitre (enucleation of the cyst). In the one case of follicular goitre the patient, a woman aged forty, three weeks after the operation got an cedematous swelling of the face, first on the side operated upon, and later also of the opposite side, and complained of headache and general malaise; the symptoms, however, disappeared entirely in the course of a month. Three of the patients were seen by the operator several years later; in one of these the remaining part of the gland was unaltered in size one year and a half after the operation; in the two remaining cases there was a distinct, though not very considerable increase of the size of the remaining part five years after the operation.

Holgir Wysind.

Reinhold (Freiburs). - The Thyroid Glant Tiatment in Mental I)isiasis. Miinchener Med. Woch.," rS94, No. 31.

IN six cases of mental diseases, combined with goitre, the author has employed feeding with the thyroid gland of the sheep. No definite influence upon the mental diseases (parosmia, mclancholic mania) could be remarked; but in all cases the circumference of the goitre decreased. The author then applied the same treatment in a healthy patient with goitre, and obtained a diminution of the goître.

Michael.

Harold, J. (London).-.-A Case of Myridema treated by Thyroid Gland.

"Lancet," Aug. 25, 1894.

THe patient was a male, agred fifty-one, with characteristic symptoms. The first treatment adopted was subcutaneous injections of glycerine extract of thyroid gland. No improvement followed and the injections caused abscess formation. Improvement followed the administration of tabloids (one to three daily), each containing five grains of the dried gland.

Dundas Grant. 